\title{
Using Logbooks to Enhance Students' Learning: Lessons From a Mixed-methods Study in an Undergraduate Surgical Rotation
}

\section{Ahmad AbdulAzeem Abdullah Omer}

Department of Surgery, Faculty of Medicine, Prince Sattam Bin Abdul Aziz University, Alkharj, KSA

ORCID:

Ahmad AbdulAzeem Abdullah Omer: https://orcid.org/0000-0001-8311-8888

Corresponding Author: Ahmad AbdulAzeem Abdullah Omer;

email: a.omer@psau.edu.sa

Received 18 July 2021

Accepted 25 August 2021

Published 30 September 2021

Production and Hosting by Knowledge E

(c) Ahmad AbdulAzeem Abdullah Omer. This article is distributed under the terms of the Creative Commons

Attribution License, which permits unrestricted use and redistribution provided that the original author and source are credited.

Editor-in-Chief:

Prof. Mohammad A. M. Ibnouf

\section{Abstract}

Background: Logbooks are frequently used in medical education to enhance and monitor students' learning. However, some barriers that may diminish their benefits have been reported. This study aims to evaluate the usefulness of logbooks to students' learning and identify the factors, which may contribute to their outcomes in learning milieus.

Methods: The study used a mixed-methods approach. Quantitative and qualitative data were collected from the medical students in the fourth- and sixth-year classes and their teachers in the department of surgery at the Faculty of Medicine at University of Tabuk in the academic year 2016-2017. Data were collected using questionnaires, focused group discussions, and personal interviews.

Results: Eighty-nine (49 fourth year and 40 sixth year) students and six teachers participated in the study. Logbooks were perceived as useful to students' learning by $83.3 \%$ of the teachers and $75.3 \%$ of the students. Logbooks enhanced students' learning through identification of areas of weaknesses, encouraged seeing more patients' problems and reading in-depth about some topics, and improved students' writing skills. Barriers to learning from logbooks included poor-quality feedback, no opportunities for feedback discussion, and unfair marking. Differences in the students' perceptions of the usefulness of logbooks were observed based on their learning stage.

Conclusion: Logbooks are useful to students' learning in many aspects; however, certain factors could diminish their benefits. Students' attitude toward the logbook was more favorable during their early clinical experience. Faculty development programs and careful supervision of students' work may improve the outcome of logbooks in clinical placements.

Keywords: logbooks, clinical teaching, written feedback, surgery, Saudi Arabia

\section{Introduction}

The use of logbooks to enhance learning is well-known in the educational enterprise, including medicine, where they have numerous advantages to learners, instructors, 
and educational institutions [1-3]. Logbooks are applied in training programs based on the philosophy of the collection of evidence that learning has taken place $[4,5]$. When designed and utilized properly, logbooks promote student learning, help in their assessment, and enhance their professional growth [6, 7]. They foster students' progress in the acquisition of knowledge and skills in patient management and care and encourage self-directed learning [8-11]. Logbooks positively influence students' learning by providing a clear picture of what they have accomplished during their learning experiences [12]. This is argued to add structure and organization and help bridge gaps in the apprenticeship model of clinical teaching that was often 'unstructured and opportunistic' [13-16].

Despite the extensive use of logbooks in undergraduate and postgraduate medical education nowadays, their application to enhance students' learning was met with equivocal and sometimes contradicting results [17-20]. Some studies showed that logbooks neither enhanced students' learning nor did they assess their competency [4, $21,22]$. Besides, it was pointed out that trainees might keep logbooks not because they are useful to their learning, but only because it is mandatory [23]. Reported limitations to learning from logbooks stem from the quality of written feedback, unavailability of discussion opportunities of feedback, and issues related to the logbook's structure and marking $[18,24,25]$.

\subsection{Setting and context}

The department of surgery in the Faculty of Medicine at University of Tabuk, in northwest Saudi Arabia, recently introduced a structured logbook to aid students' learning in the clinical courses run by the department. Before that and for around two years, the department used to administer a portfolio that was later canceled due to poor students' engagement and weak outcomes. However, it was observed that teachers' and students' opinions regarding logbook activity were still mixed. Given these contrasting opinions, and subjective decisions, it was decided to study the use of logbooks and apply the findings to inform decisions regarding teaching and learning practices in the department aiming to enhance the students' ability to learn better in the clinical environment.

\subsection{Aims and objectives}

This study aims to assess the usefulness of logbooks to promote students' learning in our context and answer the following questions: How are logbooks perceived by 
students and teachers about achieving learning outcomes? What aspects of the logbooks are experienced as enablers or barriers to learning? Furthermore, how students' individual characteristics (gender, level of study, and academic performance) affect learning experienced with logbooks?

\section{Materials and Methods}

\subsection{Study design}

The study involved a mixed-method (pragmatic) approach [27] and followed an "explanatory model" in which qualitative data were used to explain an initial set of quantitative results [28]. The quantitative part was designed to find out whether logbooks are useful to students' learning or not and assess the influence of the learner's characteristics (gender, stage of learning, and academic excellence). The qualitative part aimed to figure out how logbooks and the included feedback may support or hinder learning.

\subsection{Materials and subjects}

The study population consisted of 69 sixth-year students; 37 males and 32 females (in the 12-week Surgical Module) and 70 fourth-year students; 38 females and 32 males (in the 15-week Clinical Skills Module) in addition to six teachers involved in teaching both modules (excluding the researcher to minimize bias) in the academic year 2016-2017. Each module is run twice in a single academic year because male and female students were taught separately.

A logbook was designed to mirror the activities that students were expected to do in the hospital during their clerkships period aligned to the course objectives $[1,18]$. These include clinical, diagnostic, procedural, and patient management skills. At the beginning of each module, students were introduced to the rationale and benefits of logbooks, and how to use them effectively for their learning [29]. Students were required to submit the logbook weekly to the department in order to receive timely feedback. Each logbook received a mark out of 5 (based on the marking criteria) weekly, and all marks were averaged at the end of each module to give rise to $5 \%$ of the summative final course mark. This small mark was meant to incentivize students' work and encourage them to do their best in the logbook exercise and, at the same time, minimize significant variations in their final course grades [14]. 


\subsection{Statistics}

\subsubsection{Quantitative data}

A self-administered questionnaire was developed following a review of the relevant literature of learning from logbooks and written feedback given the study goals. Two versions of the questionnaire were developed; one for students and another for teachers, both were piloted using a selected sample of students and teachers, respectively. Each questionnaire included closed-ended and Likert-type questions with 5-point options for teachers and forced 4-point options for students (to encourage them to provide clear answers) [30]. The final logbook mark and the updated Grade Point Average (GPA) were recorded for each student.

Quantitative data were analyzed using the SPSS computer software (SPSS Inc. Chicago, Illinois) version 16, and responses were presented as frequencies and percentages of the total [31]. Alpha Cronbach statistic was used to assess the internal consistency of the questionnaire's items and validate their results [32]. Correlations were made between the students' perceptions of the usefulness of logbooks to their learning in one hand and their individual characteristics (gender, stage of learning, and level of academic performance [inferred from their GPA and logbook marks]) on the other hand, and significance of results was tested using the independent sample $t$-test. The Likert-type questions were analyzed using the Likert-scale method.

\subsubsection{Qualitative data}

Qualitative data were collected from students and teachers through focus group discussions and personal interviews, respectively. Appointments for the interviews and the focus group discussions were agreed with participants based on their convenient time and place to enhance enrollment. Two faculty members from other departments in the college and the researcher conducted the interviews and the focus group discussions. Questions posed in the focus group discussions and interviews addressed the main objectives of the study, as mentioned earlier, and prompts were provided wherever needed. Data were transcribed to papers owing to the difficulty of audiotape recording of the focus group discussions, particularly with the female students. Thematic analysis was applied to analyze the qualitative data, which were categorized under common emerging themes [33]. 


\section{Results}

Table 1 shows the number and the distribution of the student participants over the two classes in addition to the participation rates in the questionnaire and focus group discussion rounds. The Alpha-Cronbach reliability score of the students' questionnaire was 0.78 , which indicates the homogeneity and consistency of the questionnaire items.

TABLE 1: Questionnaire response rate, number, and groups of the students' focus group discussion sessions $(N=89)$

\begin{tabular}{|c|c|c|c|c|c|}
\hline \multirow[t]{2}{*}{ Questionnaire } & \multicolumn{4}{|c|}{ Response rate } & Total \\
\hline & \multicolumn{2}{|c|}{ Male students } & \multicolumn{2}{|c|}{ Female students } & \\
\hline Sixth-year students & \multicolumn{2}{|c|}{$12(32.4 \%)$} & \multicolumn{2}{|c|}{$28(82.4 \%)$} & 40 (56.3\%) \\
\hline Fourth-year students & \multicolumn{2}{|c|}{$24(63.2 \%)$} & \multicolumn{2}{|c|}{25 (78.1\%) } & 49 (70\%) \\
\hline Total & \multicolumn{2}{|c|}{$36(52.2 \%)$} & \multicolumn{2}{|c|}{$53(73.6)$} & $89(63.1 \%)^{a}$ \\
\hline \multirow[t]{3}{*}{ Gender/class } & \multicolumn{4}{|c|}{ Participation in the focus group discussion } & Total \\
\hline & \multicolumn{2}{|c|}{ Male students } & \multicolumn{2}{|c|}{ Female students } & \\
\hline & $1^{\text {st }}$ group & $2^{\text {nd }}$ group & $1^{\text {st }}$ group & $2^{\text {nd }}$ group & \\
\hline Sixth-year students & 9 & 3 & 16 & 9 & 37 (52.1\%) \\
\hline Fourth-year students & 8 & 9 & 17 & 7 & 41 (58.6\%) \\
\hline Total & \multicolumn{2}{|c|}{29 (42\%) } & \multicolumn{2}{|c|}{49 (68.1\%) } & $78(55.3 \%)^{a}$ \\
\hline
\end{tabular}

${ }^{a}$ The total number of students in both classes $=141$.

Table 2 shows students' responses to the closed-ended questions. Table 3 shows correlations between the students' perception of the usefulness of logbook and written feedback to their learning on one side and their gender and stage of learning on the other. Table 4 highlights the relationship between the students' perception of the usefulness of logbooks to their learning and their academic excellence. A statistically significant difference in the students' perception of the logbook was noted concerning their stage of learning; the fourth-year students perceived the logbook more positively than their senior counterparts. Gender and academic excellence did not give rise to significant differences.

TABLE 2: Students' overall responses to the closed-ended questions $(N=89)$.

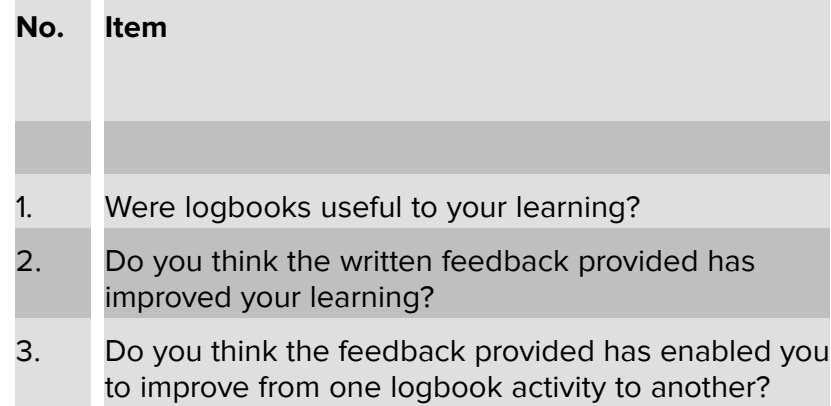

\begin{tabular}{|c|c|c|}
\hline \multicolumn{2}{|c|}{ Students' responses } & \multirow{2}{*}{$\begin{array}{l}\text { Total } \\
\text { number of } \\
\text { responses }\end{array}$} \\
\hline es & No & \\
\hline 7 (75.3\%) & 22 (24.7\%) & 89 \\
\hline O (67.4\%) & 29 (32.6\%) & 89 \\
\hline 3 (70.8\%) & 26 (29.2\%) & 89 \\
\hline
\end{tabular}


TABLE 3: Students' responses to the closed-ended questions according to their level of study and gender $(N=89$; fourth year $=49$, sixth year $=40$, males $=37$, females $=52)$.

\begin{tabular}{|c|c|c|c|c|c|c|}
\hline \multirow[t]{2}{*}{ No. } & \multirow[t]{2}{*}{ Item } & \multicolumn{2}{|c|}{ Fourth-year students } & \multicolumn{2}{|c|}{ Sixth-year students } & \multirow[t]{2}{*}{$P$-value } \\
\hline & & Useful & Not useful & Useful & Not useful & \\
\hline 1. & $\begin{array}{l}\text { Do you think the logbook } \\
\text { was useful to your learning } \\
\text { during the course? }\end{array}$ & 45 (91.8\%) & 4 (8.2\%) & 22 (55\%) & 18 (45\%) & 0.000 \\
\hline \multirow[t]{2}{*}{2.} & $\begin{array}{l}\text { Have you been involved in } \\
\text { receiving written feedback } \\
\text { during your previous } \\
\text { studies? }\end{array}$ & Yes & No & Yes & No & 0.186 \\
\hline & & 29 (61.7\%) & $18(38.3 \%)$ & 30 (75\%) & $10(25 \%)$ & \\
\hline 3. & $\begin{array}{l}\text { Do you think the written } \\
\text { feedback provided has } \\
\text { improved your learning? }\end{array}$ & 39 (79.6\%) & $10(20.4 \%)$ & 21 (52.5\%) & 19 (47.5\%) & 0.007 \\
\hline 4. & $\begin{array}{l}\text { Do you feel the feedback } \\
\text { provided has enabled you } \\
\text { to improve from one } \\
\text { logbook activity to } \\
\text { another? }\end{array}$ & 36 (73.5\%) & $13(26.5 \%)$ & 27 (67.5\%) & $13(32.5 \%)$ & 0.538 \\
\hline \multirow[t]{2}{*}{ No. } & Item & \multicolumn{2}{|c|}{ Male students } & \multicolumn{2}{|c|}{ Female students } & $P$-value \\
\hline & & Useful & Not useful & Useful & Not useful & \\
\hline 1. & $\begin{array}{l}\text { Do you think the logbook } \\
\text { was useful to your learning } \\
\text { during the course? }\end{array}$ & 29 (78.4\%) & $8(21.6 \%)$ & 38 (73.1\%) & 14 (26.9\%) & 0.568 \\
\hline \multirow[t]{2}{*}{2.} & $\begin{array}{l}\text { Have you been involved in } \\
\text { receiving written feedback } \\
\text { during your previous } \\
\text { studies? }\end{array}$ & Yes & No & Yes & No & 0.847 \\
\hline & & 24 (66.7\%) & 12 (33.3\%) & 35 (68.6\%) & 16 (31.4\%) & \\
\hline 3. & $\begin{array}{l}\text { Do you think the written } \\
\text { feedback provided has } \\
\text { improved your learning? }\end{array}$ & 27 (73\%) & 10 (27\%) & 33 (63.5\%) & 19 (36.5\%) & 0.345 \\
\hline 4. & $\begin{array}{l}\text { Do you feel the feedback } \\
\text { provided has enabled you } \\
\text { to improve from one } \\
\text { logbook activity to } \\
\text { another? }\end{array}$ & 27 (73\%) & $10(27 \%)$ & 36 (69.2\%) & $16(30.8 \%)$ & 0.702 \\
\hline
\end{tabular}

TABLE 4: Correlation between students' perceptions of usefulness of logbook to their learning and their final logbook mark and GPA ( $N=89)$.

\begin{tabular}{|c|c|c|c|c|c|c|c|c|}
\hline \multirow[t]{2}{*}{ Usefulness/ Item } & \multicolumn{3}{|c|}{ Useful } & \multicolumn{3}{|c|}{ Not useful } & \multirow{2}{*}{$\begin{array}{l}\text { Total } \\
\text { number of } \\
\text { responses }\end{array}$} & \multirow[t]{2}{*}{$P$-value } \\
\hline & $\mathbf{N}$ & Mean & SD & $\mathbf{N}$ & Mean & SD & & \\
\hline Final logbook mark & 57 & 4.52 & 0.33 & 19 & 4.3 & 0.68 & $76^{*}$ & 0.07 \\
\hline GPA & 49 & 4.01 & 0.43 & 20 & 4.04 & 0.35 & $69^{*}$ & 0.29 \\
\hline
\end{tabular}

*Missing values. 
Table 5 compares the overall students' responses to the Likert-type questions according to their level of study and gender. A statistically significant difference was observed between the students based on their learning stage.

TABLE 5: Comparison between the overall response of the students to the Likert-type questions according to their level of study and gender $(N=89)$.

\begin{tabular}{ll|l|l|l|l|} 
Level of study & N & Mean & SD & P-value* \\
Fourth year & $44^{* *}$ & 3.56 & 0.66 & 0.016 \\
\hline Sixth year & 40 & 3.23 & 0.58 & \\
\hline Gender & Level of study & N & Mean & SD & P-value* \\
\hline Males & Fourth year & 24 & 3.53 & 0.52 & 0.194 \\
\hline & Sixth year & 12 & 3.28 & 0.53 & \\
\hline Females & Fourth year & $19^{* *}$ & 3.60 & 0.82 & 0.062 \\
\hline & Sixth year & 28 & 3.2 & 0.61 & \\
${ }^{*} P \leq 0.05 ;{ }^{* *}$ missing values. & & & &
\end{tabular}

While all teacher participants perceived their feedback as useful to students, only five (83.3\%) indicated that the logbook is useful to students' learning.

\subsection{Results of the thematic analysis of the qualitative data}

Figure 1 summarizes the factors perceived by the study participants to support or hinder learning from logbooks emerging from the focus group discussions and interviews. Figure 2 summarizes the factors that converged on and influenced students' acceptability of written feedback as emerged from the focus group discussions and interviews.

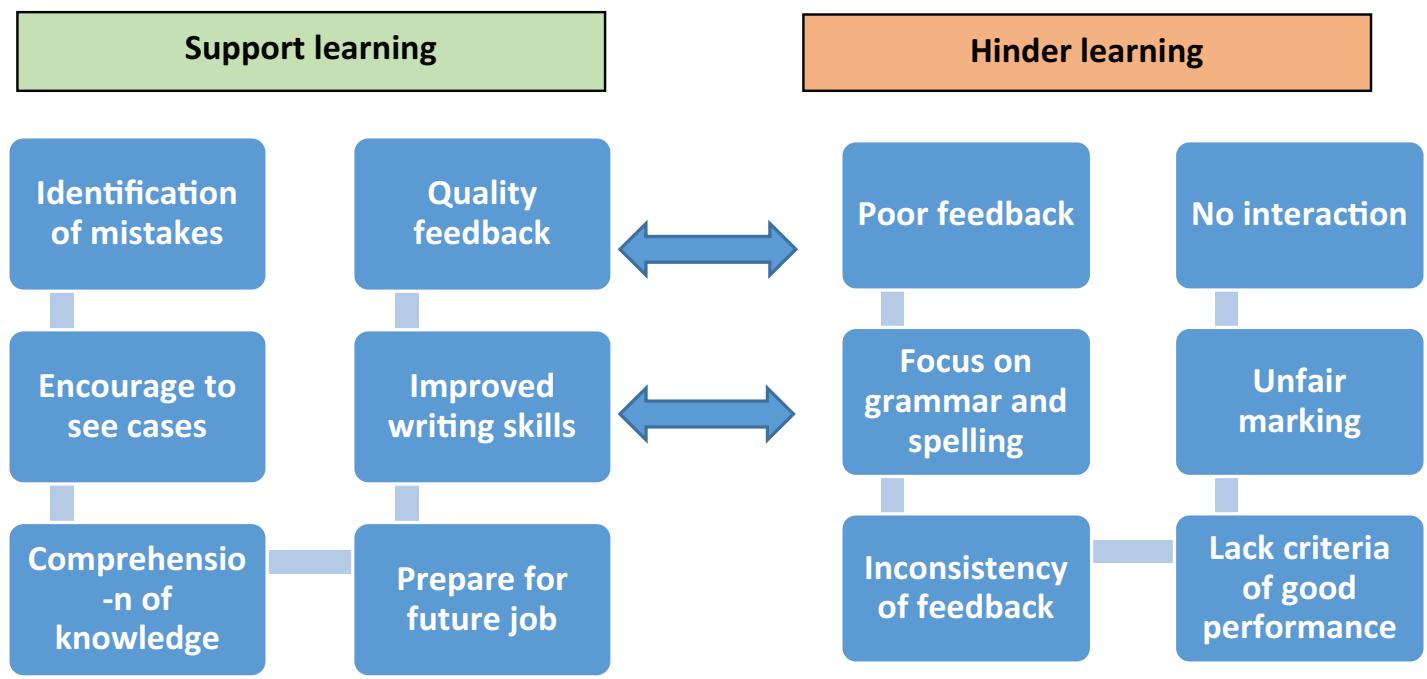

Figure 1: Overarching themes, subthemes, and their relationship to each other regarding the perceived usefulness of logbooks to student learning (arrows indicate a dual role for the factors). 


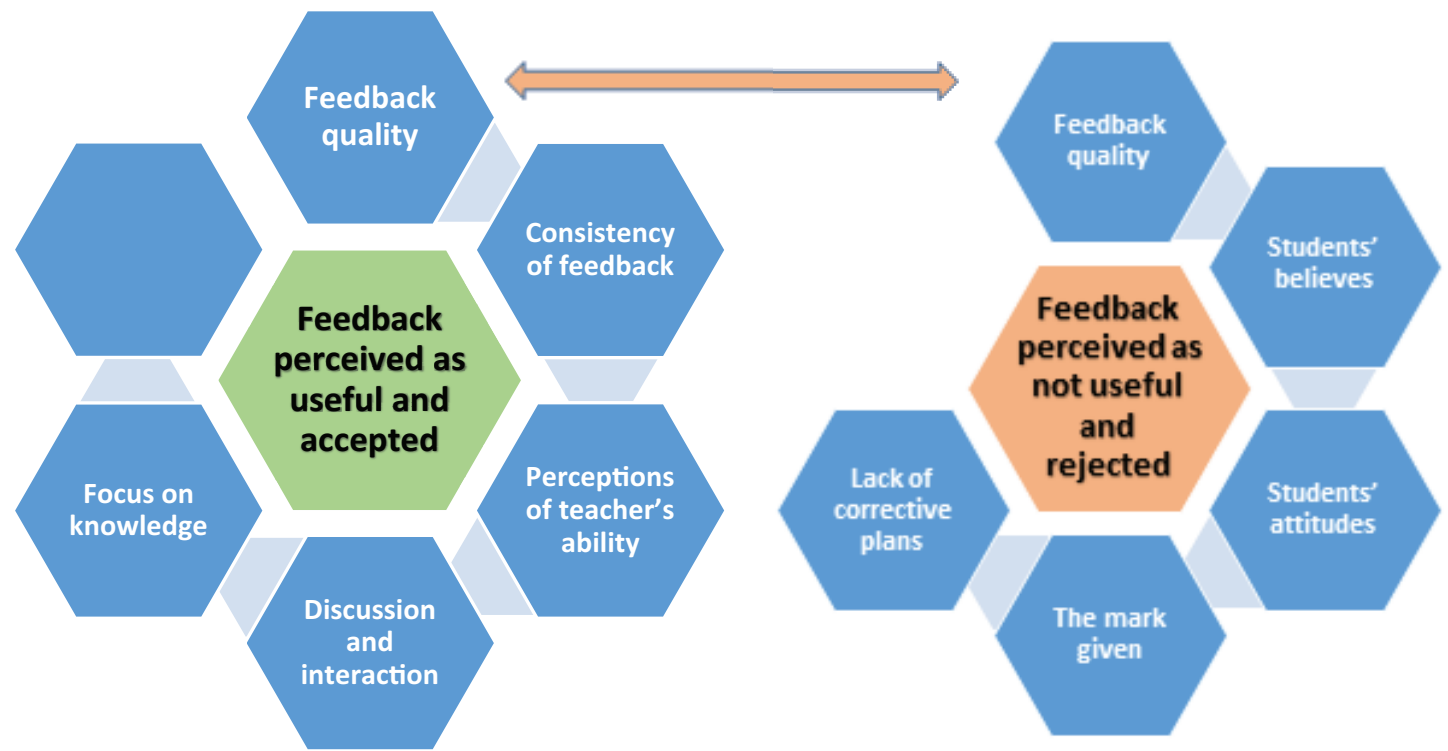

Figure 2: Overarching themes, subthemes, and their relationship to each other regarding the perceived usefulness and acceptability of feedback (arrow indicates a dual role for the factor).

\section{Discussion}

This study aimed to investigate the usefulness of logbooks to students' learning from students' and teachers' perspectives and how they may influence learning, whether positively or negatively. Study findings will be discussed under three headings: perceptions of the usefulness of logbooks to learning, the role of logbooks as promoters and hinderers of learning, and the role of the individual characteristics of learners in the process.

\subsection{Perceptions of the usefulness of logbooks to students' learning}

The usefulness of logbooks to enhance students learning is frequently reported as mentioned earlier, however, some studies have shown the contrary. For example, Busemann et al. (2011) elaborated on the use of a logbook to enhance students' learning in a surgical clerkship. They reported that $<35 \%$ of the students perceived logbook as useful to their learning [34]. They argued that, although the logbook is a powerful learning tool, it should be adapted to the students' needs or otherwise may demotivate them and inhibit their learning (e.g., teacher's guidance and structured training).

Although both students and teachers perceived the logbook and written feedback as useful, contrary to their teachers, some students were not pleased with the quality of feedback they received in logbooks, which they often described as unclear, unfair, 
inconsistent, and does not involve suggestions for improvement. This was evident in some students' comments like:

"I used to receive the same comments, no improvement because it did not show me how to do that." SY6F (please refer to the list of abbreviations at the end of the article)

"Sometime feedback is contradicting, what is correct for one teacher is not necessarily so for others." SY4F

Such discrepancies in the perceptions of feedback between students and teachers are one of the documented barriers to effective use of feedback as a powerful tool for learning. Carless (2006), and Abraham and Singaram (2019) have reasoned discrepancy in the feedback perception to the different interpretations of the feedback message between students and teachers [35, 36]. In consonance, Boud and Molloy (2013) have affirmed the importance of interaction and closure of the loop in the feedback process, which depicts feedback as a dynamic process between the feedback parties [37]. However, and in relevance to the context of this study, Rae and Cochrane (2008) highlighted the difficulty of the provision of feedback in modular systems of teaching where, owing to the tight schedules, the feedback provided tend to be summative rather than formative [38]. Also, Dahllof et al. (2004) noticed that although students in their study perceived feedback as useful, they still suffered different opinions on clinical knowledge among teachers and insufficient feedback volume. They argued, "Students' need of feedback is difficult to satisfy" [39; p. 169]. For instance, a fourth-year student stated:

"Some teachers' comments were based on their experience and did not necessarily agree with other teachers or, sometimes, with what is reported in the literature." SY4F

Despite the difficulties in the process of feedback execution, many reports have encouraged teachers to invest time and effort to provide meaningful feedback and avail opportunities to discuss the logbook work with their students [4, 15, 24, 40, 41].

\subsection{Logbooks as promoters of students' learning}

\subsubsection{Role of feedback}

Many students valued the logbook's role in showing them their mistakes and aspects of their work which require revision and correction and, occasionally, suggestions on 
how to improve [18]. Such benefits coincide with the findings of Barbieri et al. (2015) and are exemplified in the following students' quotes:

"It was helpful to know your mistakes and avoid them in the future." SY4F

"It gives different views of points and experiences from teachers' side on how to improve." SYF6

Similar to the findings of Smith et al. (2014), Safari et al. (2017), and other researchers, such benefits can be attributed to the regular feedback that students received through the weekly submission of the logbook and demonstrates the vital role of timely feedback in the process $[4,36,42,43]$. This ties in with the teachers' results in the current study and underlines one of the essential advantages of the logbook to learning; assessment of students' progression in acquisition of knowledge and skills during their learning, which was frequently reported [10, 44-46]. Carless (2006) and Carless et al. (2011) have pointed to the role of the short feedback cycles in the multistage tasks strategy pertinent to the logbook exercise which enable teachers to see the "echo" of their feedback; the learner's response and improvement $[35,47]$. In the same vein, a teacher commented:

"They come to know what was positive and what was negative regarding their performance, they learned about the deficiencies and the strengths in their work and then planned to improve it." T1

The logbook demonstrated how students assimilated and responded to the feedback on previous work to show improvement in their future assignments. Barbieri et al. (2015) have shown similar results in an online logbook project in an anesthesia training program, in addition to some other researchers. Therefore, logbooks may potentially improve the structure of training and enable students to demonstrate progression in learning and accomplishment of educational objectives [18, 43, 47].

\subsubsection{Provision of opportunities to learn from patients}

Many students and teachers indicated that the logbook encouraged seeing more and a variety of cases and learn from them. The logbook and the accompanying feedback were perceived as a trigger for learning. Similar results were shown by Chiesa et al. (2013) using logbooks in a clinical rotation and Safari et al. (2014) applying logbooks in anatomy teaching $[15,43]$. The following quotes demonstrate such benefits to students learning: 
"It allows writing in-depth about some cases, and the feedback helps to refine the documented information." SY6M

"I was encouraged to see variety of cases and read about them." SY4FM

"It encouraged students to see cases in the hospital and how to communicate with patients and how to do procedures." T1

Logbooks promote learning from the individual cases reported in them and may prove exposure to an appropriate case-mix which are essential parts of the clinical learning. Watters et al. (2006) commented on the use of logbooks in a surgical rotation in Australia and asserted that individual cases reported in logbooks drive students learning. Wright et al. (2017) and Buckley et al. (2009) have shown similar supporting evidence of logbooks and portfolios in the medical education [9, 20, 21]. However, and interestingly, some fourth-year students claimed not to benefit from seeing cases in the hospital. Two of them commented:

"Cases were repeating over time thus the benefit was limited." SY4M

"It was just repetition, doing the same task again and again." SY4M

This aligns with the reported difficulties that junior students may experience in learning from logbooks. Raghoebar-Krieger et al. (2001) indicated that junior students may find difficulty to report all the cases that they came across in the hospital because their knowledge and skills at that stage are insufficient [14]. They added, junior students engage in a process of socialization due to their unfamiliarity with hospital environments, and may, therefore, overlook some of the cases that they have seen during their training. Interestingly, Uther and Ooi (2016) have noticed that the students in their series tended to report the same cases regardless of the hospital or season of training. They reasoned such observation to the tendency of students to overlook some cases [48]. Poor students' guidance due to clinicians' heavy workloads and busy schedules, in addition to the burden of data entry and limited opportunities to interact with patients on the learner's side may also be responsible factors [1, 9, 50]. Likewise, Alabbad et al. (2019) have argued that senior students may benefit from logbooks more than their junior counterparts, where they tend to select cases that provide more significant learning opportunities; however, no correlation to their final course grades was observed [4]. By contrast, Shaban et al. (2018) have noticed that the final-year medical students in their series have seen less than the expected cases and procedures in a shift of emergency medicine [49]. It was argued that students might not learn from the experiences that they 
encounter in the hospitals, and to prove the contrary, evidence (outcome measure) that learning has ensued should be provided [49]. Watters et al. (2006) commented on the use of a logbook system in a surgical placement and argued that an evidence of learning from the logbook exercise and the contribution of supervisors to students' achievements should be demonstrated [21]. Therefore, careful supervision and mentoring of junior students with their logbook work in addition to claiming students' follow-up exercises (e.g., assignments, write-ups, and case-based discussion) based on their logbooks' entries might be reasonable strategies to heighten their engagement and benefit from the exercise.

\subsubsection{Improve writing skills}

Many students, also supported by some teachers, indicated that the logbook had improved their writing skills. This applies to the medical terms and knowledge as well as to the English language and grammar. This is highlighted in the following students' comments:

"It was useful for correction of spelling mistakes and writing in grammatical order." SY6M

"It helped me to improve my spelling mistakes." SY4M

"It improved their handwriting, spelling and English language. In general, this is one of their few chances in the college to learn that." T4

However, other students suffered due to too much focus of feedback on grammar and spelling mistakes at the cost of medical information. A student commented:

"Concentration was mainly on grammar and handwriting, feedback on knowledge was ignored." SY6F

Ruscher et al. (2010) studied feedback behaviors in a multiracial setting and asserted that high-quality feedback has to focus on student's work leading to transferable skills rather than just correcting grammatical and spelling errors [51]. Moreover, Bing-You et al. (1997) indicated that students may tend to disregard feedback that is "stylish" in nature and if there is too much focus on unimportant areas [52]. Therefore, a balanced written feedback that addresses students' work mainly from clinical and disciplinary points of view with attention to the principles of English language and scientific writing is often worth consideration. 


\subsubsection{Relation to students' future career}

A unique advantage of the logbook indicated by some teachers in this study is that it prepares students for their future career; however, students did not mention that. $A$ teacher said:

"The nature of exercises in the logbook, e.g., writing medical notes and doing patient follow-up, is the same kind of practice that they would carry out in their future career." T24

It was reported that portfolio work increased students' preparedness to conduct the same tasks in the future and taught them to keep data to perform an audit, all of which have essential implications for their professional life [9, 18, 21]. For instance, Buckley et al. (2009) argued that keeping a reflective learning document in the undergraduate phase prepare students for the higher stages of training [20]. In the same vein, Shahi et al. (2015) evaluated students' participation in three training settings through analysis of their logbook entries. They reported higher patient engagement and better students' preparedness for future practice in the rural setting [46]. If this information is communicated to the students early in the logbook trial, it might have increased their engagement and benefit from the exercise and perhaps should be considered in future experimentation $[18,43]$.

\subsection{Barriers to learning from logbooks}

On the other hand, poor-quality feedback, subjectivity in marks and the marking process, and issues related to the logbook structure (e.g., a strictly prescribed format) were perceived as barriers to learning from logbooks. These were reflected in the following students' quotes:

"Marking was not fair, and I have received marks from only a few teachers." SY6F

"The logbook was structured to just "fill-in-the-blank;" we wanted more space to write freely, more freedom in writing." SY6F

In consonance, Svendsen et al. (2019) recommended a user-friendly logbook and warned against a bureaucratic one which involves extensive load of data entry [1]. Likewise, Jud et al. (2020) was skeptic about the possibility of using logbooks appropriately to enhance students' learning unless proper guidance and supervision of students 
in the wards is implemented [17]. Involving enthusiastic physicians and mentors among the hospital staff in regular review and monitoring of their students' work supplemented with faculty development programs were proposed to increase the acceptability of the logbook and feasibility of the process $[29,40,53]$. Besides, effort should aim to improve the structure of the logbook to adjust the burden of data entry and refine rubrics to add fairness to the marking process $[1,18,49]$.

\subsection{Role of learners' individual characteristics}

\subsubsection{Stage of learning}

The fourth-year students perceived the logbook activity more significantly useful to their learning than the sixth-year students. Al-Haqwi et al. (2012), in a study of feedback in Saudi Arabia, found that medical students' perceptions of feedback were more positive in early undergraduate years, which they attributed to the more prolonged exposure of senior students to weaknesses in the feedback practice. They argued, the longer exposure enabled senior students to produce more accurate judgments about the process than their junior counterparts [54]. As such, students' engagement with the logbook might decrease if careful planning, follow-up, and meticulous measures are not taken to ensure proper implementation of the logbook, and, with time, senior students are more likely affected. This may also point to the possible role of the academic environment and the hidden curriculum, which often sends strong messages about the process and demand further analysis in future studies.

\subsubsection{Level of academic performance}

No difference was found in the students' perception of the usefulness of logbooks based on their academic performance. This is in contrast to some studies, which indicated that students who have good knowledge and clinical skills and excel in their academic performance appreciate feedback as more useful than their counterparts who are less knowledgeable $[52,54]$. In addition, it was also noted that high-achieving students concentrate on the feedback message and try to understand the meaning behind it [36]. However, the restricted ranges of GPA and logbook marks may have resulted in poor discrimination among the students' academic abilities and contributed to this finding [24]. Besides, some GPA and logbook marks were missing, and this could have affected the data analysis and the conclusion made out of it. 


\subsubsection{Gender}

Similarly, gender did not give rise to differences in the students' perception of the logbook, which is in line with Fong et al. (2016) [55]. However, there were marked differences in the participation rates in this study between female and male students, particularly in the sixth-year, with a larger number of females being involved $(82.4 \%$ and $32.4 \%$, respectively, as shown in Table 1). This difference could be interpreted as a more positive attitude, higher interest, and better engagement of female students with the logbook experience than their male counterparts. In contrast, Streeter (2013) showed better engagement of males than females in using a music therapy logbook for patients with neurological disabilities, which they attributed to more confidence and positive attitude that males had toward the logbook activity [56]. Further studies to assess learners' characteristics in engagement with and benefit from logbooks are required.

\section{Limitations}

Some factors may have limited the findings of this study and are worth to be mentioned. The sample size, particularly that of teachers, was small. The study involved students at specific academic years and in selected courses, which may have introduced a selection bias. However, there is no logical reason to expect different results if students at other learning stages in our context were involved. Also, the results of this study might not be generalizable to other settings. Nevertheless, the findings of this study would provide essential data to curriculum planners and course coordinators to set the stage for improving the procedure and outcome of logbooks in our academic environment.

\section{Conclusion}

Logbooks are one of the tools that are used to enhance learning in the realm of medical education, where they might foster students' learning through multiple aspects. It encourages students to see cases in the hospital from which they can learn a lot. It is a mechanism to show them their mistakes and suggest to them plans for improvement. Besides, it improves their writing skills of medical notes and their use of English. However, several barriers to effective use of logbooks were also reported. These include: poor-quality feedback, biased marking, absence of dialogue in the feedback process, and problems with the structure and acceptability of the logbook. 
To improve students' learning from the logbook, faculty members should be trained on constructive feedback principles. In addition, discussion of the logbook work and careful supervision of students, particularly at the beginning of their clinical training are essential to promote learning from logbooks.

\section{Acknowledgments}

The author would like to thank Dr. Mandy Moffat, who kindly supervised this work. He is also grateful to the fourth- and sixth-year students in the college and his colleagues in the department of surgery who shared their precious time during data collection.

\section{Ethical Considerations}

This study has been approved by the ethical committee of University of Tabuk. The principles of ethical conduction of research according to the Declaration of Helsinki [26] were followed except that the researcher has participated in data collection because no other suitable alternative was found. The researcher acknowledges that this could have influenced participants' responses in some way.

\section{Competing Interests}

The author reports no conflict of interest. The author alone is responsible for all work submitted in this manuscript.

\section{Availability of Data and Material}

All relevant data of this study are available to any interested researchers upon reasonable request to the corresponding author.

\section{Funding}

None. 


\section{Abbreviations}
S: Student
Y: Year
M: Male
F: Female
T: Teacher
4: Fourth year
6: Sixth year

\section{References}

[1] Svendsen, Ø., Helgerud, C., Duinen, A., et al. (2019). Evaluation of a surgical task sharing training programme's logbook system in Sierra Leone. BMC Medical Education, vol. 19, article 198.

[2] Beasley, S., McBride, C., and Pearson, M. (2011). Use of the operative logbook to monitor trainee progress, and evaluate operative supervision provided by accredited training posts. The Surgeon, vol. 9, no. 1, pp. S14-S15.

[3] Saber, M., Firouzi, S., and Azizi, F. (2008). The logbook effect on clinical learning of interns in internal ward rotation in Shiraz University of Medical Sciences. Journal of Medicine Education, vol. 12, no. 34, pp. 61-65.

[4] Alabbad, J., Abdul Raheem, F., Almusaileem, A., et al. (2018). Medical students' logbook case loads do not predict final exam scores in surgery clerkship. Advances in Medical Education and Practice, vol. 9, no. 9, pp. 259-265.

[5] Snadden, D. and Thomas, M. (1998). The use of portfolio learning in medical education. Medical Teacher, vol. 20, no. 3, pp. 192-199.

[6] Corbetta, L., Arru, L., Mereu, C., et al. (2019). Competence and training in interventional pulmonology. Panminerva Medica, vol. 61, no. 3, pp. 203-231.

[7] Simpson, J. G., Furnace, J., Crosby, J., et al. (2002). The Scottish doctor-learning outcomes for the medical undergraduate in Scotland: a foundation for competent and reflective practitioners, Medical Teacher, vol. 24, no. 2, pp. 136-143.

[8] Kennedy, G., Nicola, J., Rea, M., et al. (2019). Prompting medical students to selfassess their learning needs during the ageing and health module: a mixed methods study. Medical Education Online, vol. 24, article 1579558, pp. 1-12. 
[9] Wright, H., Maley, M., Playford, D., et al. (2017). Paediatric case mix in a rural clinical school is relevant to future practice. BMC Medical Education, vol. 17, article 237.

[10] Harvey, P., Radomski, N., and O'Connor, D. (2013). Written feedback and continuity of learning in a geographically distributed medical education program. Medical Teacher, vol. 35, no. 12, pp. 1009-1013.

[11] Taylor, D. and Hamdy, H. (2013). Adult learning theories: implications for learning and teaching in medical education: AMEE Guide No. 83. Medical Teacher, vol. 35, no. 11, pp. e1561-e1572.

[12] Perella, P., Palmer, E., Conway, R., et al. (2019). A retrospective analysis of case-load and supervision from a large anaesthetic logbook database. Anaesthesia, vol. 74, no. 12 , pp. 1524-1533.

[13] Starmer, D., House, C., and Langworthy, K. (2019). Student exposure to cancer patients: an analysis of clinical logbooks and focus groups in clinical year medical students. Journal of Cancer Education, vol. 35, pp. 760-765.

[14] Uther, P. and Ooi, C. (2016). Paediatric clinical exposure for medical students: Are they seeing enough? Journal of Paediatrics and Child Health, vol. 52, vol. 12, pp. 1086-1089.

[15] Chiesa, D., Escalante, R., van Wyk, J., et al. (2013). Evaluating logbooks to improve clerkship learning experiences. Medical Education, vol. 47, no. 11, pp. 1122-1123.

[16] Shumway, L. M. and Harden, R. M. (2003). AMEE Guide No. 25. The assessment of learning outcomes for the competent and reflective physician. Medical Teacher, vol. 25 , no. 6 , pp. 569-584.

[17] Jud, S., Cupisti, S., Frobenius, W., et al. (2020). Logbooks alone are not enough: initial experience with implementing a logbook for medical students in a clinical internship in gynecology and obstetrics. European Journal of Medical Research, vol. 25, article 15.

[18] Barbieri, A., Giuliani, E., Lazzerotti, S., et al. (2015). Education in anesthesia: three years of online logbook implementation in an Italian school. BMC Medical Education, vol. 15, article 14.

[19] Huang, G., Almeida, J., and Roberts, D. (2012). Reaching the limits of mandated selfreporting: Clinical logbooks do not predict clerkship performance. Medical Teacher, vol. 34, no. 3, pp. e185-e188.

[20] Buckley, S., Coleman, J., Davison, I., et al. (2009). The educational effects of portfolios on undergraduate student learning: a Best Evidence Medical Education (BEME) systematic review. BEME Guide No. 11. Medical Teacher, vol. 31, no. 4, pp. 282298. 
[21] Watters, D., Green, A., and Van Rij, A. (2006). Requirements for trainee logbooks. ANZ Journal of Surgery, vol. 76, no. 3, pp. 181-184.

[22] Nixon, M. (2000). The anaesthetic logbook - a survey. Anaesthesia, vol. 55, no. 11, pp. 1076-1080.

[23] Mangione, S. and Peitzman, S. (1999). Revisiting physical diagnosis during the medical residency: is it time for a logbook - and more. Academic Medicine, vol. 47, no. 5, pp. 467-469.

[24] Jackson, J., Kay, C., Jackson, W., et al. (2015). The quality of written feedback by attendings of internal medicine residents. Journal of General Internal Medicine, vol. 30, no. 7, pp. 973-978.

[25] Dowden, T., Pittaway, S., Yost, H., et al. (2013). Students' perceptions of written feedback in teacher education: ideally feedback is a continuing two-way communication that encourages progress. Assessment \& Evaluation in Higher Education, vol. 38, no. 3, pp. 349-362.

[26] World Medical Association. (2001). World Medical Association Declaration of Helsinki; Ethical Principles for Medical Research Involving Human Subjects. Bulletin of the World Health Organization, vol. 79, no. 4, pp. 373-374.

[27] Creswell, J. and Clark, V. (2011). Designing and conducting mixed methods research ( $3^{\text {rd }}$ ed.). USQ: SAGE Publications Inc.

[28] Schifferdecker, K. and Reed, V. (2009). Using mixed methods research in medical education: basic guidelines for researchers. Medical Education, vol. 43, no. 7, pp. 637-644

[29] Schuttpelz-Brauns, K., Narciss, E., Schneyinck, C., et al. (2016). Twelve tips for successfully implementing logbooks in clinical training. Medical Teacher, vol. 38, no. 6, pp. 564-569.

[30] Boone, H. N., Jr. and Boone, D. A. (2012). Analyzing Likert data. Journal of Extension, vol. 50, no. 2 , article 2TOT2.

[31] Allen, E. and Seaman, C. (2007). Statistics roundtable: Likert scales and data analysis. Quality Progress, vol. 40, no. 7, pp. 64-65.

[32] Deniz, M. S. and Alsaffar, A. A. (2013). Assessing the validity and reliability of a questionnaire on dietary fibre-related knowledge in a Turkish student population. Journal of Health, Population and Nutrition, vol. 31, no. 4, pp. 497-503.

[33] Delva, D., Sargeant, J., Miller, S., et al. (2013). Encouraging residents to seek feedback. Medical Teacher, vol. 35, no. 12, pp. e1625-e1631. 
[34] Busemann, A., Bernstorff, W., and Heidecke, C. D. (2011). Consequences drawn from the evaluation of logbook-based surgical training for final year students. Zentralblatt fur Chirurgie, vol. 137, no. 2, pp. 165-172.

[35] Carless, D. (2006). Differing perceptions in the feedback process. Studies in Higher Education, vol. 31, no. 2, pp. 219-233.

[36] Abraham, R. and Singaram, V. (2019). Using deliberate practice framework to assess the quality of feedback in undergraduate clinical skills training. BMC Medical Education, vol. 19, article 105.

[37] Boud, D. and Molloy, E. (2013). Rethinking models of feedback for learning: the challenge of design. Assessment \& Evaluation in Higher Education, vol. 38, no. 6, pp. 698-712.

[38] Rae, A. and Cochrane, D. (2008). Listening to students; How to make written assessment feedback useful. Active Learning in Higher Education, vol. 9, no. 3, pp. $217-230$.

[39] Dahllof, G., Tsilingaridis, G., and Hindbeck, H. (2004). A logbook for continuous self-assessment during 1 year in pediatric dentistry. European Journal of Paediatric Dentistry, vol. 5, no. 3, pp. 163-169.

[40] Fida, N., Hassanien, M., Shamim, M., et al. (2018). Students' perception of portfolio as a learning tool at King Abdulaziz University Medical School. Medical Teacher, vol. 40, no. 1, S104-S113.

[41] Mokhtarpour, E., Amini, M., Mousavinezhad, H., et al. (2016). Evaluation of the strengths and weaknesses of community-based education from the viewpoint of students. Journal of Advances in Medical Education \& Professionalism, vol. 4, no. 4, pp. 195-201.

[42] Smith, L., Adam, L., Moffat, S., et al. (2017). How do educators in one New Zealand undergraduate Bachelor of Oral Health course teach and nurture professionalism? European Journal of Dental Education, vol. 22, no. 2, e212-e220.

[43] Safari, M., Ghahari, L., and Taheri, M. (2014). Effective use of logbook on the learning of anatomy of the head and neck. International Journal of Current Life Sciences, vol. 4 , no. 8, pp. 4312-4315.

[44] Mollahadi, M., Khademolhoseini, S. M., Mokhtari-Nouri, J., et al. (2018). The portfolio as a tool for mentoring in nursing students: a scoping review. Iranian Journal of Nursing and Midwifery Research, vol. 23, no. 4, pp. 241-247.

[45] Zafar, S., Hafeez, A., Qureshi, F., et al. (2009). Structured training in management of emergencies in mothers, babies and children in a poorly resourced system: logbooks to document skill use. Resuscitation, vol. 80, pp. 449-452. 
[46] Shahi, R., Walters, L., Ward, H., et al. (2015). Clinical participation of medical students in three contemporary training models. Medical Education, vol. 49, no. 12, pp. 12191228.

[47] Carless, D., Salter, D., Yang, M., et al. (2011). Developing sustainable feedback practices. Studies in Higher Education, vol. 36, no. 4, pp. 395-407.

[48] Raghoebar-Krieger, H., Sleijfer, D., Bender, W., et al. (2001). The reliability of logbook data of medical students: an estimation of interobserver agreement, sensitivity and specificity. Medical Education, vol. 35, no. 7, pp. 624-631.

[49] Shaban, S., Canakci, M., Kuas, C., et al. (2018). Do senior medical students meet recommended emergency medicine curricula requirements? BMC Medical Education, vol. 18, article 8.

[50] Starmer, D. (2019). Medical student exposure to cancer patients whilst on clinical placement: a retrospective analyses of clinical log books. Journal of Cancer Education, vol. 34, pp. 671-676.

[51] Ruscher, J., Wallace, D., Walker, K., et al. (2010). Constructive feedback in cross-race interactions. Group Processes \& Intergroup Relations, vol. 13, no. 5, pp. 603-619.

[52] Bing-You, R., Paterson, J., and Levine, M. (1997). Feedback falling on deaf ears: residents' receptivity to feedback tempered by sender credibility. Medical Teacher, vol. 19, no. 1, pp. 40-44.

[53] Shah, S., Ross, O., Pickering, S., et al. (2017). Tablet e-logbooks: four thousand clinical cases and complications e-logged by 14 nondoctor anesthesia providers in Nepal. Anesthesia \& Analgesia, vol. 125, no. 4, pp. 1337-13341.

[54] Al-Haqwi, A., Al-Wahbi, A., Abdulghani, H., et al. (2012). Barriers to feedback in undergraduate medical education Male students' perspective in Central Saudi Arabia. Saudi Medical Journal, vol. 33, no. 5, pp. 557-561.

[55] Fong, C., Warner, J., Williams, K., et al. (2016). Deconstructing constructive criticism: the nature of academic emotions associated with constructive, positive, and negative feedback. Learning and Individual Differences, vol. 49, pp. 393-399.

[56] Streeter, E. (2013). Taking gender into account: brief report on a survey of music therapists' attitudes for future use of a proposed computer aided evaluation system: the music therapy logbook. The Arts in Psychotherapy, vol. 40, pp. 404-408. 